\title{
Penentuan Kuantitas Produksi Kue Brownies yang Optimal pada Model Persediaan Periode Tunggal
}

\author{
Vini Damayanti", M. Yusuf Fajar
}

Prodi Matematika, Fakultas Matematika dan Ilmu Pengetahuan Alam, Universitas Islam Bandung, Indonesia.

*vinidamayanti3@gmail.com, myusuffajar@unisba.ac.id

\begin{abstract}
Inventory is an important part of a manufacturing company, both before the production process begins, during the production process or after the production process is complete. Inventory control in a company must be carried out as optimally as possible. Shortage or excess of inventory will cause losses for the company. Holding costs will be large if there is excess inventory. With the availability of inventory management, it can anticipate a surge in demand from consumers. Inventory management is also used to optimize inventory as possible to reduce inventory costs. In this thesis, analyze the optimal quantity of brownie cake production using a single period model. In this model, it must determine the level of inventory, the holding cost of inventory, and the cost of shortage of inventory. Once determined, it can be seen from the optimal brownies cake production results. Based on the results of the data analysis of the optimal quantity of brownie cake production, it can be seen that the optimal of 8 packages or 200 pcs with an expected total cost of Rp. 12.825.540.
\end{abstract}

Keywords: Inventory, Single Period Model, Brownie cake products.

\begin{abstract}
Abstrak. Persediaan merupakan bagian yang penting dalam suatu perusahaan manufaktur, baik sebelum proses produksi dimulai, saat proses produksi berlangsung maupun setelah proses produksi selesai. Pengendalian persediaan dalam suatu perusahaan harus dilakukan seoptimal mungkin. Kekurangan maupun kelebihan persediaan akan dapat menimbulkan kerugian bagi perusahaan. Biaya penyimpanan akan menjadi besar bila terjadi kelebihan persediaan. Dengan adanya manajemen persediaan dapat mengantisipasi lonjakan permintaan dari konsumen. Manajemen persedian juga berguna untuk mengoptimalkan persediaan seoptimal mungkin guna mengurangi biaya persediaan. Pada skripsi ini, di lakukan analisis penentuan kuantitas produksi kue brownies yang optimal dengan menggunakan model periode tunggal. Pada model ini harus menentukan level inventory, biaya simpan, dan biaya kekurangan persediaan. setelah ditentukan maka dapat dilihat hasil produksi kue brownies yang optimal. Berdasarkan hasil analisis data kuantitas produksi kue brownies yang optimal sebanyak 8 pack atau 200 pes dengan ekspektasi ongkos total Rp. Rp. 12.825.540.
\end{abstract}

Kata Kunci: Persediaan, Model Periode Tunggal, Produk kue brownies. 


\section{A. Pendahuluan}

1. Suatu industri atau manufaktur yang memproduksi barang atau jasa tentu menginginkan keuntungan dari penjualan produknya. Proses produksi tentunya tidak terlepas dari persediaan. Menurut Herjanto (1999), pengaturan persediaan memiliki pengaruh terhadap berbagai aspek operasi, aspek pemasaran, dan keuangan. Berkaitan dengan persediaan ini terdapat konflik kepentingan diantara fungsi bisnis tersebut. Keuangan menghendaki tingkat persediaan yang rendah, sedangkan pemasaran dan operasi menginginkan tingkat persediaan yang tinggi agar kebutuhan konsumen dan kebutuhan produksi dapat dipenuhi.

2. Persediaan merupakan bagian yang penting dalam suatu perusahaan manufaktur, baik sebelum proses produksi dimulai, saat proses produksi berlangsung maupun setelah proses produksi selesai. Menurut Assauri (2008), pengendalian persediaan dalam suatu perusahaan harus dilakukan seoptimal mungkin. Kekurangan maupun kelebihan persediaan akan dapat menimbulkan kerugian bagi perusahaan. Biaya penyimpanan akan menjadi besar bila terjadi kelebihan persediaan. Dengan adanya manajemen persediaan dapat mengantisipasi lonjakan permintaan dari konsumen. Manajemen persedian juga berguna untuk mengoptimalkan persediaan seoptimal mungkin guna mengurangi biaya persediaan.

3. Sejak tahun 1970 an, seorang ibu sangat berantusias membuat beragam macam kue di rumahnya. Semula, ia hanya berangkat dari kue-kue sederhana seperti bolu kukus, kue lapis dan beberapa kue rumahan lainnya. Banyak pelanggan yang menyukai aneka rasa kue-kue tersebut.

4. Metode periode tunggal merupakan model persediaan yang pengadaan persediaan hanya satu kali untuk memenuhi permintaan satu periode. Pada model ini harus menentukan level inventory, biaya simpan, dan biaya kekurangan persediaan.setelah ditentukan maka dapat dilihat hasil produksi roti yang optimal dan mengetahui ekspektasi biaya total minimum.

\section{B. Tinjauan Pustaka}

Inventory dalam bahasa Indonesia berarti persediaan. Sedangkan sistem inventory memiliki makna pengaturan persediaan dan berkaitan dengan aktivitas logistik sebuah perusahaan. Dimana kegiatan dari sistem tersebut termasuk dalam pengecekan dan penyediaan stok bahan baku atau barang setengah jadi ataupun barang jadi, untuk kelancaran proses produksi atau pemenuhan permintaan pelanggan.

Kuantitas persediaan adalah jumlah persediaan yang dapat dihasilkan dalam suatu periode tertentu. Kuantitas persediaan perlu dipertimbangkan dan disesuaikan dengan banyaknya permintaan. Barang yang tidak tahan lama tidak dapat disimpan lama, oleh karena itu bila barang yang diperlukan tergolong barang yang tidak tahan lama maka tidak perlu disimpan dalam jumlah banyak. Sedangkan untuk barang yang memiliki sifat tahan lama, maka tidak ada salahnya perusahaan menyimpannya dalam jumlah besar.

Biaya persediaan terdiri dari seluruh pengeluaran, baik yang langsung maupun tidak langsung yang berhubungan dengan pembelian, persiapan, dan penempatan persediaan untuk dijual. Biaya persediaan merupakan salah satu faktor kelancaran penjualan, sehingga persediaan harus dikelola secara tepat. Biaya-biaya yang berkaitan dengan persediaan yaitu biaya simpan, biaya penyiapan, biaya pemesanan, biaya kehabisan dan kekurangan. Permintaan adalah suatu proses dalam meminta sesuatu atau sejumlah barang yang dibeli atau diminta pada suatu harga dan waktu tertentu. Permintaan berkaitan dengan keinginan konsumen akan suatu barang dan jasa yang ingin dipenuhi.

Fungsi densitas merupakan suatu konsep dasar dalam statistika yaitu sebagai penentu besar probabilitas untuk selang yang diberikan, Tujuan penaksiran fungsi densitas ini adalah untuk mendapatkan kurva fungsi densitas yang merupakan kurva mulus dengan variasi sampling tidak besar dan informasi penting dari data tidak hilang. 


\section{METODE PERIODE TUNGGAL}

Dalam hal ini metode periode tunggal digunakan untuk menganalisis kuantitas produksi yang optimal pada kue brownies. Dimana kue brownies merupakan produk yang mempunyai masa kadaluwarsa yang singkat, yaitu tiga hari. Apabila pada hari pertama penjualan produk kue brownies tidak habis maka akan dijual untuk keesokan harinya. Jika produk tidak habis atau terjual dalam waktu tiga hari maka produk sudah tidak bisa dikonsumsi lagi.

\section{Pembahasan}

Data yang digunakan dalam penelitian ini secara garis besar diambil dari sumbernya meliputi data primer dan data sekunder. Data primer diperoleh melalui pengamatan langsung terhadap kegiatan pengelolaan produksi kue brownies di toko " $\mathrm{X}$ " dan wawancara dengan karyawan serta pihakpihak yang berkepentingan. Data sekunder yang digunakan merupakan data pola penjualan produk roti selama 4 bulan dan data penunjang yang diperoleh melalui literatur, dokumen dan informasi dari karyawan toko "X".

Data yang dibutukan dalam pemecahan masalah ini adalah:

1. Data jumlah persediaan roti Toko "X" periode Agustus 2018

2. Data jumlah penjualan roti Toko " $X$ " periode Agustus 2018

Data biaya penyimpanan persediaan roti Toko "X" periode Agustus 2018. Biaya yang meliputi biaya penyimpanan adalah biaya listrik.

\section{PERHITUNGAN BERDASARKAN MODEL PERIODE TUNGGAL}

Karena persediaan $(\mathrm{Q})$ lebih tinggi dari permintaan $(\delta$ ) maka tidak terjadi kekurangan persediaan.

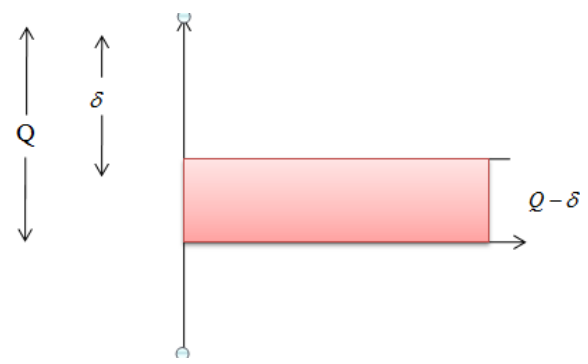

Dalam model periode tunggal akan dicari yang pertama adalah menentukan level inventory, menentukan biaya simpan, menentukan biaya persediaan, dan menentukan ekspektasi ongkos total, sebagai berikut:

1. Menentuka Lgvel Inventory

$$
I L(Q)=\left\{\begin{array}{cc}
0 & \delta<Q \\
0 \quad & \delta \geq Q
\end{array}\right.
$$

2. Menentukan Ekspektasi Biaya Simpan

$$
\mathrm{E}(\text { biaya simpan })=h \int_{0}^{Q} I L(Q) \phi(\delta) d \delta \text { sehingga } h \int_{0}^{Q} Q-\delta \phi(\delta) d \delta
$$

karena permintaan $(\delta)$ 


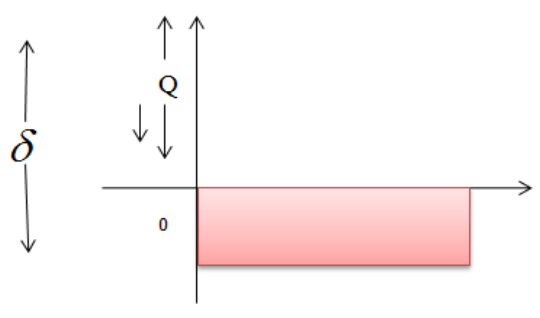

3. Menentukan Biaya Persediaan

$$
S I(Q)=\left\{\begin{array}{cc}
0, & \delta \leq Q \\
\delta-Q & , \quad \delta>Q
\end{array}\right.
$$

4. MenentukanEkspektasi Biaya Kekurangan

$$
\text { E[biaya kekurangan }]=p \int_{Q}^{\infty}(\delta-Q) \phi(\delta) d \delta
$$

Biaya item $=c(Q-x), x=$ on hand sebelum order tiba.

Menentukan Ekspektasi Biaya Total adalah :

$$
\begin{aligned}
& E[T C(Q)]=c(Q-x)+h \int_{0}^{Q}(Q-\delta) \phi(\delta) d \delta+p \int_{Q}^{\infty}(\delta-Q) \phi(\delta) d \delta \\
& \frac{d E[T C(Q)]}{d Q}=c+h \int_{0}^{Q} \phi(\delta) d \delta-p \int_{Q}^{\infty} \phi(\delta) d \delta=0 \\
& \text { Karena } \int_{Q}^{\infty} \phi(\delta) d \delta=1-\int_{0}^{Q} \phi(\delta) d \delta, \text { maka } \\
& \frac{d E[T C(Q)]}{d Q}=c+h \int_{0}^{Q} \phi(\delta) d \delta-p\left(1-\int_{0}^{Q} \phi(\delta) d \delta\right)=0 \\
& \mathrm{c}+\mathrm{h} \int_{0}^{Q} Q(\delta) d \delta-p+p \int_{0}^{Q} Q \delta d \delta=0 \\
& (\mathrm{p}+\mathrm{h}) \int_{0}^{Q} Q \delta d \delta=p-c \\
& \int_{0}^{Q} Q \delta \delta \quad=\frac{p-c}{p+h}
\end{aligned}
$$

\section{KASUS PERMINTAAN DISKRIT}

Pada kasus permintaan diskrit ini akan dicari ekspektasi ongkos total dan kuantitas produksi kue brownies yang optimal dengan mencari biaya simpan, biaya kekurangan persediaan, dan harga barang atau produk.

Ekspektasi ongkos total :

$$
E[T C(Q)]=c(Q-x)+h \sum_{\delta=0}^{Q}(Q-\delta) \phi(\delta)+p \sum_{\delta=Q+1}^{\infty}(\delta-Q) \phi(\delta)
$$

Syarat perlu agar ekspektasi ongkos total minimum adalah : 


$$
E[T C(Q-1)] \geq E[T C(Q)] \text { dan } E[T C(Q+1)] \geq E[T C(Q)]
$$

Dari ekspektasi ongkos total didapat:

$$
\begin{aligned}
& E[T C(Q-1)]=c(Q-1-x)+h \sum_{\delta=0}^{Q-1}(Q-1-\delta) \phi(\delta)+p \sum_{\delta=Q}^{\infty}(\delta-Q+1) \phi(\delta) \\
& E[T C(Q)]=c(Q-x)+h \sum_{\delta=0}^{Q}(Q-\delta) \phi(\delta)+p \sum_{\delta=Q+1}^{\infty}(\delta-Q) \phi(\delta) \\
& E[T C(Q-1)]-E[T C(Q)]=p-c-(h+p) P(\delta \leq Q-1) \geq 0 \\
& P(\delta \leq Q) \geq \frac{p-c}{p+h}
\end{aligned}
$$

Dengan $Q^{*}$ yang harus memenuhi

$$
P\left(\delta \leq Q^{*}-1\right) \leq \frac{p-c}{p+h} \leq P\left(\delta \leq Q^{*}\right)
$$

Berdasarkan hasil pengumpulan data yang diperoleh dari Toko " $X$ " permintaan/penjualan produk roti menggunakan satuan pack, 1 pack yang berisi 25 pcs adalah sebagai berikut:

Tabel 1. Hasil Pengumpulan Data

\begin{tabular}{|c|c|}
\hline Permintaan/Pack & Frekuensi \\
\hline 7 & 2 \\
\hline 8 & 6 \\
\hline 9 & 3 \\
\hline 10 & 9 \\
\hline 11 & 4 \\
\hline 12 & 4 \\
\hline 13 & 1 \\
\hline Jumlah & 29 \\
\hline
\end{tabular}

Fungsi densitas dari masing-masing data permintaan ditunjjukan pada Tabel 3.3 berikut ini:

Table 2. Hasil Perhitungan Fungsi Densitas

\begin{tabular}{|c|c|c|}
\hline Permintaan/Pack & Frekuensi & $\begin{array}{l}\text { Fungsi } \\
\text { Densitas }\end{array}$ \\
\hline 7 & 2 & 0.068 \\
\hline 8 & 6 & 0.207 \\
\hline 9 & 3 & 0.103 \\
\hline 10 & 9 & 0.310 \\
\hline 11 & 4 & 0.138 \\
\hline 12 & 4 & 0.138 \\
\hline 13 & 1 & 0.034 \\
\hline & 29 & 1 \\
\hline
\end{tabular}


Biaya simpan adalah biaya yang dikeluarkan toko jika persediaan tidak habis dan dijual keesokan harinya. Biaya simpan ini meliputi biaya listrik bagi pendingin atau pemanas serta penerangan ruangan penyimpanan barang.

Biaya simpan $(\mathrm{h})=10 \% \times$ Harga barang $(\mathrm{c})$

$=10 \% \times$ Rp. $52.000=$ Rp. 5.200 per pcs

Biaya simpan untuk 1 pack (25 pcs) adalah Rp. 130.000

Jadi, biaya simpan untuk per pes adalah Rp. 5.200 dan untuk 1 pack adalah Rp.130.000

Biaya kekurangan persediaan ini diberlakukan ketika persediaan dari cabang toko " $\mathrm{X}$ " habis atau tidak ada, maka pihak toko harus menanggung biaya untuk mengambil persediaan dari cabang toko "X" yang lain sebesar Rp. 20.000, dengan biaya untuk ongkos kirim. Sehingga di asumsikan biaya kekurangan persediaan dari harga barang Rp.52.000 menjadi Rp.72.000.

Biaya kekurangan persediaan (p) per pack adalah Rp. 1.800.000

Harga barang adalah harga dari produk yang dijual yang harganya sudah ditentukan oleh pihak toko yaitu sebesar Rp.52.000 per pcs. Harga barang (c) per pack adalah Rp. 1.300.000

Setelah diketahui biaya simpan, biaya kekurangan persediaan dan harga barang maka dapat dicari kuantitas produksi yang optimal.

Penentuan kuantitas produksi yang optimal, yaitu mencari nilai $Q^{*}$ yang memenuhi pertidaksamaan berikut:

$$
\begin{aligned}
& P\left(\delta \leq Q^{*}-1\right) \leq \frac{1.800 .000-1.300 .000}{1.800 .000+130.000} \leq P\left(\delta \leq Q^{*}\right) \\
& P\left(\delta \leq Q^{*}-1\right) \leq 0,259 \leq P\left(\delta \leq Q^{*}\right)
\end{aligned}
$$

Dari tabel 3.3, diperoleh:

$$
P(\delta \leq 7)=0,068 \leq 0,259 \leq 0,275=P(\delta \leq 8)
$$

Jadi diperoleh kuantitas produksi yang optimal atau Q* adalah 8 .

Setelah diketahui kuantitas peroduksi yang optimal maka selanjutnya akan dicari ekspektasi ongkos total.

Ekspektasi Ongkos total dihitung melalui langkah-langkah berikut ini:

$$
\begin{aligned}
& \text { Mencari } \sum_{\delta=0}^{Q}(Q-\delta) \phi(\delta) \quad=(8-7) \times 0.068+(8-8) \times 0.206=0,068 \\
& \text { Mencari } \sum_{\delta=Q+1}^{\infty}(\delta-Q) \phi(\delta)=(9-8) \times 0.103+(10-8) \times 0.310+(11-8) \times 0.138+(12- \\
& 8) \times 0.138+(13-8) \times 0.034 \\
& =1,859
\end{aligned}
$$

Cara menghitung ekspektasi ongkos total yaitu mengalikan harga barang per pack dengan hasil kuantitas produksi yang optimal ditambah harga simpan dikalikan dengan hasil dari $\sum_{\delta=0}^{Q}(Q-\delta) \phi(\delta)$ ditambahkan harga kekurangan persediaan dikalikan dengan hasil $\sum_{\delta=Q+1}^{\infty}(\delta-Q) \phi(\delta)$ Ekspektasi ongkos total adalah :

$$
\begin{aligned}
E[T C(Q)] & =c(Q)+h \sum_{\delta=0}^{Q}(Q-\delta) \phi(\delta)+p \sum_{\delta=Q+1}^{\infty}(\delta-Q) \phi(\delta) \\
= & 1.300 .000(8)+130.000(0,068)+1.800 .000(1,859) \\
= & \text { Rp. } 12.825 .540
\end{aligned}
$$




\section{Kesimpulan}

Penentuan kuantitas produksi kue brownies menggunakan model persediaan periode tunggal karena masa kadaluarsa kue brownies sangat singkat. Dengan menghitung biaya simpan, biaya kekurangan persediaan, harga barang, dan fungsi densitas permintaan, dapat diperoleh kuantitas produksi kue brownies yang optimal sebanyak 8 pack dan ekspektasi ongkos total Rp. 12.825.540.

\section{Daftar Pustaka}

Assauri, Sofjan. 2008. Manajemen Produksi dan Operasi. Jakarta : Lembaga Penerbit Fakultas Ekonomi Universitas Indonesia.

Handoko. 2000. Manajemen Personalia dan Sumber Daya Manusia, Edisi II,

Cetakan Keempat Belas. Yogyakarta: BPFE

Jane. Metode Pengendalian Bahan Baku. http://file2shared.wordpress.com.2009.

Diakses pada tanggal 13 Juni 2009 pukul 18.02.

Novia widya utami. April, 2018. "Mengenal Sistem Inventory dan Cara Mudah Pengelolaannya." https://www.jurnal.id/id/blog/2018-mengenal-sistem-inventory-dan-cara-mudahpengelolaannya/

Ristono. 2009. Manajemen Persediaan. Yogyakarta: Graha Ilmu.

Rangkuti, Freddy. Manajemen Persediaan Aplikasi dibidang Bisnis. Jakarta:

Rajawali Pers, 2000

(n.d.). Retrieved Juli 3, 2014, from http://id.wikipedia.org/wiki/Permintaan

Team Teaching Kimia Anorganik. 2008. Modul Praktikum. Gorontalo:UNG 